\title{
Energy management in buildings obtained through multi-criteria assessment system
}

\author{
L. M. Moga ${ }^{1} \&$ A. Puskas ${ }^{2}$ \\ ${ }^{1}$ Department of Buildings and Management, \\ Technical University of Cluj-Napoca, Romania \\ ${ }^{2}$ Department of Structures, Technical University of Cluj-Napoca, \\ Romania
}

\begin{abstract}
Energy is a variable cost that can be controlled. A significant percentage of the energy used on a national and international level is consumed in buildings, which means there are considerable potential for savings and a corresponding need for responsible behavior. Careful use of energy and resources represents a technical, economic and ecological challenge as well as being one which is important for survival and sustainable living. The European energy policy has a defined direction towards the preservation of energy and improvement of indoor environmental quality in buildings through the adoption of the European's Commission's (EC) recast Energy Performance of Buildings Directive (EPBD). The research development directions take into analysis the complexity of the current situation and are oriented towards clear goals such as: energy savings and usage of green energies use of eco-materials, and the incorporation of innovative technologies and systems. Other important aspects of the interdisciplinary research of sustainable development directions are related to aspects of the community life, integration in the city's structure and in the territory, and the relation with the natural environment. The paper will present briefly the design and implementation stage of multi criteria assessment system developed in a national grant.

Keywords: energy management, sustainable buildings, multi-criteria analysis, environmental assessment, national grant, energy efficiency.
\end{abstract}




\section{Introduction}

Energy management within buildings generally results in an absolute reduction in the use of energy. The interventions can save energy, reduce costs, and preserve natural resources while reducing environmental pollution. There are not only immediate benefits for the building owner and user but also long-term public benefits when energy consumption is managed better for buildings. Energy management therefore makes business sense as well as broader economic, social and environmental sense. For these reasons, local and national governments have set energy efficiency targets related to buildings. Energy management benefits are cumulative over time. Each day opportunities to save energy and minimize the energy demand are lost without realizing these benefits if energy management is not implemented. Energy management is an approach that considers the energy related impacts and interactions of all building component, including the building site, i.e. its envelope (walls, windows, doors and roof), its heating, ventilation and air-conditioning system, and its lighting, controls and equipment.

The definition of "building performance" term is very complex, since different actors in the building sector have differing interests and requirements. For example investors are more interested in economic performance whereas tenants are more interests in health and comfort related aspects. Therefore, when developing an energy management policy and strategy it is important to consider all the key factors. The idea of sustainable development principles requires the application of a strategy that promotes energy efficiency and rational use of natural resources at national level. Since the construction sector is one of the most important energy consumers, implementation of measures aimed at reducing consumption at this level, plays a primary role. For the comparative multi-criteria analysis of the residential dwellings or sustainable buildings, it is necessary to follow certain required steps. These steps must include technical studies on the performance of sub-systems of buildings or residential dwellings. Assessment of a building will imply measuring how well or poorly that building is performing, or is likely to perform, against a declared set of criteria.

Beginning with the 70 s research programs on life-cycle energy analyses were developed but without putting an increase accent on the environmental aspects and building impact [1]. Several complex environmental and energy assessment methodologies have been developed around the world since year 2000. Some of the well-known methodologies are: UK Building Research Establishment Environmental Assessment Method (BREEAM), Leadership in Energy and Environmental Design (LEED) from US, Hong Kong Building Environmental Assessment Method (HK-BEAM), Japanese Comprehensive Assessment Scheme for Building Environmental Efficiency (CASBEE), and so on. The tools cover different phases of a building's life cycle and take different environmental issues into account. These tools are global, national and, in some cases, local.

The system criteria of the existing assessment methods and their rating levels and scoring were analysed and their positive and negative aspects have been highlighted and discussed. A main idea was outlined, that is all assessment 
methods although are converging towards the same goal, they are not yet in a harmonization process for a methodology that could be universally valid.

Because of the existence of a non-performing housing stock on a national level [2], although those are built with high quality materials and technologies, an urgent implementation of an assessment system was required.

\section{An overview of environmental building assessment methods}

Building assessment methods are considered one of the most effective and potent means to improve buildings performance and to promote higher expectation and demand. The assessment methods emerged in order to provide an objective valuation of resource use, ecological impact, energy use and indoor environmental quality. The field of building environmental assessment has matured remarkably since the introduction of the BREEAM in 1990. Since then a rapid increase in the number of methods either in use or in development phase was observed. Assessment methods witnessed a considerable success and their widespread awareness has developed the necessary interest in creating a positive change in the field of sustainable buildings [3].

The first version of BREEAM for offices was launched in 1993 and the second revision in September 1998. A version for non-domestic premises was BREEAM 2004 which covered various types of buildings including offices, industrial premises, retail outlets, schools etc. [4]. BREEAM EcoHomes was replaced by the Code for Sustainable Homes in 2007 for assessment of new homes, based on the former version. The Code, scored new homes on Performance levels in six categories with a six-level system (i.e. Code Level 3 is similar to EcoHomes Very Good) to achieve sustainability standards. Beginning with the $1^{\text {st }}$ of August 2008 buildings have been assessed under BREEAM 2008 that replaced BREEAM 2006 [5]. BREEAM 2008 was replaced by BREEAM 2011 for new buildings but also for assessing new build extensions to existing buildings. The standard continued to certify buildings as PASS (30\%), GOOD $(45 \%)$, and VERY GOOD (55\%), EXCELLENT $(70 \%)$ or OUTSTANDING $(85 \%)$. The change came from the fact that the 2011 did not set just the minimum criteria around reducing a building's $\mathrm{CO}_{2}$ emission rate, but it also requires reductions in energy demand and energy consumption i.e. energy efficiency improvements. Also some credits such as Life Cycle Impacts have been expanded to cover all buildings, not just Education and Healthcare as in BREEAM 2008.

Although the assessment methods originated in developed countries a crosscultural transferability of assessment methods through exchange and "borrowing" methods activities have begun. Beside the positive aspects of the exchange, also negative aspects were identified. An inappropriate implementation of the method due to cultural and local issues could be detrimental to environmental progress [6].

BREEAM was taken as a reference model when similar assessment methods were developed in Hong Kong, New Zealand, Canada, Singapore and Norway [7]. 
HK-BEAM was one of the assessment method developed based on a BREEAM template in 1996. Although it had an UK template, the overall structure and detailed criteria were modified to suit the Hong Kong context [6]. First products of HK-BEAM released in 1996 covered new and existing airconditioned office buildings. The versions released in 1998 were revisions of its earlier products but were complemented by a version for new residential projects. Other two pilot versions of a third generation of UK-BEAM were released in 2003, versions that represented significant upgrades on the prior versions. New types of buildings could be assessed by giving a rating system. LEED had an important influence in this stage of developing the method. Compared to the structure of the earlier versions that were coming from the BREEAM template, the new categories were organized under Site Aspects, Material Aspects, Energy Use, Water Use, indoor Environmental, Quality and Innovations and Performance Enhancements. Also the level of performance changed to Platinum, Gold and Silver along with a Bronze rating similar to LEED's certified level. In 2005 the current versions of HK-BEAM were released [8].

LEED assessment method is owned and administrated by the US Green Building Council (USGBC), council that wanted to accelerate the adoption of green building practices, technologies, policies and standards. The method appeared in 1995 and the first draft proposal for LEED Building Rating System for New and Existing Office Buildings was released in 1996 [9]. Another version was introduced in April 1999 called LEED-version 1.0 and in March 2000 LEED for New construction 2.0 was introduced. Performance issues were organized into six categories: Sustainable Sites, Water Efficiency, Energy and Atmosphere, Materials and Resources, Indoor Environmental Quality, and Innovation and Design Process. This version was manly applicable to new design and major renovations of new commercial, institutional and high-rise residential buildings. A revision of LEED 2.0 was released in 2002 LEED-NC 2.1 and in 2005 LEEDNC 2.2 was launched. The LEED v3 referred to as LEED 2009 incorporated the existing commercial and institutional building rating systems: New Construction, Core and Shell, Commercial Interiors, Existing Buildings: Operations and Maintenance and Schools. Depending on the total credits, a building receives a rating level of "bronze", "silver", "gold" or "platinum". A new version called LEED v4 is due to appear in June 2013.

Through years changes appeared to the performance criteria, credit scales and baseline building requirements in BREEAM, HK-BEAM, LEED and other assessment methods, due to the fact that knowledge, experience and available data is under a continuous increasing process.

\section{The national assessment methodology}

A national grant called SIR-(i.e. "Integrated solutions of collective housing rehabilitation in Romania") began the work for the elaboration and implementation of a multi-criteria analysis specific to the types of buildings and conditions from Romania. The aim was to identify problems arising from 
retrofitting (or thermal rehabilitation) processes and provide integrated solutions for improved comfort, reduced energy consumption and pollutant emissions. Another objective was to identify ways of implementing a sustainable development strategy in the retrofitting actions of collective housing in Romania.

The achievement of these goals was made possible through a research grant represented by three universities "Ion Mincu" University of Architecture and Urbanism, Technical University of Cluj-Napoca and Technical University Gh. Asachi Iasi, and research institutions that promote innovative solutions in terms of new technologies and a new approach to retrofitting of buildings, in the spirit of sustainable development principles integrating critic views of civil society and local authorities.

A thorough analysis was undertaken based on various criteria: selecting sources of information, data processing and conclusions presented by the team have been useful in defining a set of criteria appropriate to SIR research [10].

The system criteria of the existing assessment methods e.g. BREEAM, LEED, CASBEE, HK-BEAM and their rating levels and scoring were analysed and positive and negative aspects have been highlighted and discussed.

In regard to positive aspects the following were identified:

- existence of evaluation criteria organized on various factors;-

- analysis of construction life cycle stages;

- existence of criteria that takes into account the natural environment-built environment relationship;

- encouraging the use of renewable resources, green energy and organic materials;

- integration of various elements capable of ensuring sustainable development;

- highlighting of strategies and local priorities, by their application for the various stages of planning/ designing;

- granting certification labelling

- providing a "code"/an application guide.

As negative aspects, the following were identified:

- there was not enough attention given for criteria concerning the human factor, e.g. education, information, strategies, specific local priorities, relation with the community were not emphasized;

- for some of the assessment tools, the categories set out to assess, overlap or do not appear sufficiently clear;

- not enough connection between the stages of planning- design;

- not enough consideration for the life cycle assessment of construction;

- elements such as resources or environmental aspects (material, relationship with the natural environment) were not clearly highlighted.

Thus, key concepts on performance and quality were outlined and clarified, and methodologies were structured. Although all assessment methods converge towards the same goal, they are not yet in a harmonization process for a methodology that could be universally valid.

Minnesota Sustainable Design Guide was chosen as the standard methodology to be followed in the development of the assessment methodology. The guide educates and assists architects, building owners, occupants, educators, 
students, and the general public concerning sustainable building design. The Guide is a design tool that can be used to overlay environmental issues on the design, construction, and operation of both new and renovated buildings. It can be used to set sustainable design priorities and goals; develop appropriate sustainable design strategies; and to determine performance measures to guide the sustainable design and decision-making processes. It can also be used as a management tool to organize and structure environmental concerns during the design, construction, and operations phases. They methodology was designed to be compatible with national US guidelines such as LEED while maintaining regional values, priorities and requirements [11]. The guidelines of the methodology are organized into the following main categories: Performance Management, Site and Water, Energy and Atmosphere, Indoor Environmental Quality and Materials and Waste. In the case of Major Renovations, some of the required guidelines depend on the scope of the renovation, and are noted as such. At section "Energy and Atmosphere" the required performance criteria is to ensure that annual energy costs are reduced by at least $30 \%$ as required by the Minnesota Legislature. For the Renewable energy performance criteria, new or renovated buildings must provide $2 \%$ of energy needs with on-site solar or wind renewable sources Also energy use associated with plug loads and process loads in buildings must be reduced and energy conservation should be achieved with the lowest reasonable environmental impacts [12]

For a better systemization, the development of the national assessment method was divided into four main phases:

- the first stage was the documentation for the project;

- the second phase was the generation of an analysis and diagnosis multi-criteria system for buildings to be rehabilitated and the development of a computer program in this purpose;

- the third phase consisted in choosing a particular case for applying the generated theories in the previous phases, in order to generate a rehabilitation concept and methodology of study and analysis;

- the fourth phase was to establish practical implementation strategies for the obtained concepts by building partnerships and establishing meetings with local government representatives of institutions and various departments, and also with project partners.

\section{Results and discussion}

First, a review of the performance assessment regulations of buildings and urban ensembles was conducted, supplemented by a list of the most current developments in the field, contained in European and International projects. A list of criteria that were considered to be necessary in order to elaborate a proper methodology for the multi-criteria analysis was drafted, and the information was organized in a standardized form.

The second phase established a model for assessing the performance of several variants, by developing a software program for residential buildings/ complexes and commercial buildings. Several models for analysis and lists of 
criteria were considered, and the analysis computer program was developed by considering the Minnesota criteria. A system for evaluation and certification of buildings was proposed and a selection of technologies, materials and solutions for use in integrated retrofitting solutions were chosen.

For the case study from the third phase of the project, a set of buildings in the "Politehnica" area from Bucharest were chosen. The case is representative for the rehabilitation process of housing units. After a survey of the area, a questionnaire was filled by the beneficiaries in order to identify the specific problems. Then, a proposal was made for the rehabilitation complex, with solution for sustainable architecture, incorporating new materials, green technologies, modern and efficient, renewable energy, from urban scale to construction detail. The proposed solutions for this case can become an example of integrated rehabilitation designed to open new perspectives of study [13].

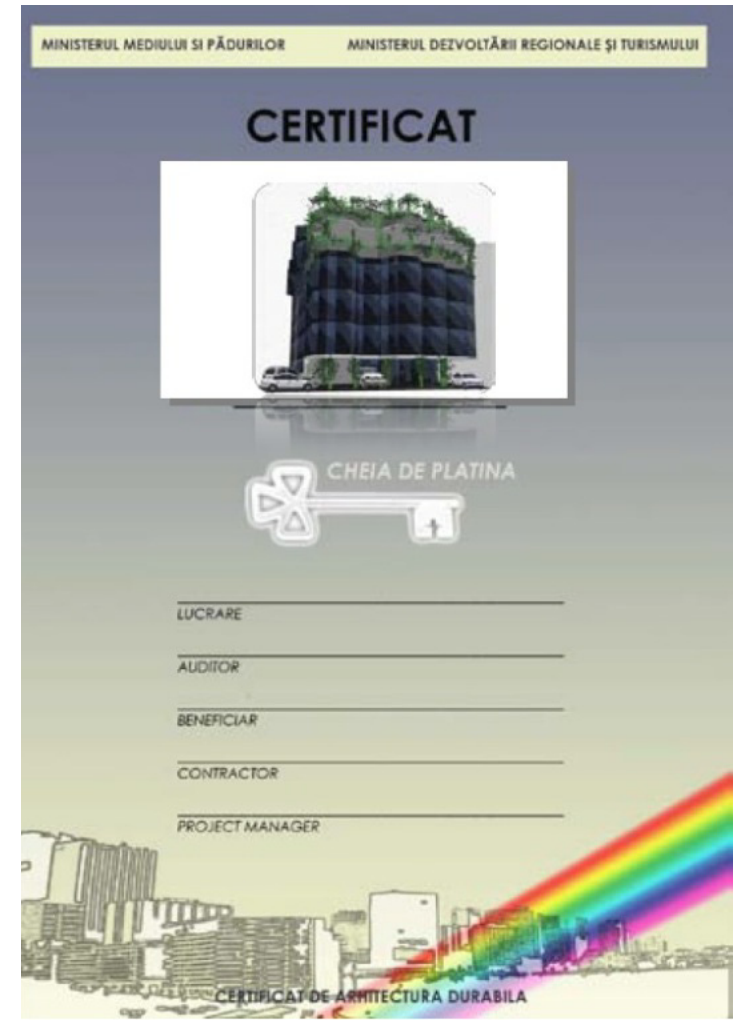

Figure 1: Example of sustainable architecture certificate for a platinum key building [13].

The Multi-Criteria Assessment System proposes a system of criteria which covers all fields, from the psycho-social to the ecological impact on the 
environment, generating particular scoring criteria. The necessary minimum score is 44 points grouped on three main domains:

- less than 6 points for criteria documentation like design, construction, impact site;

- at least 26 points for criteria concerning materials, energy and water consumption;

- at least 12 points for criteria concerning health and well-being, operation, maintenance and facilities.

Another major objective of the project was to develop and to provide a multicriteria analysis and sustainable architecture certificates, according to points accumulated by the assessed building which are calculated by the multi criteria assessment software. The quality of the construction is certified by granting "keys" bronze, silver (52-67 points), gold (69-81 points) or platinum (82-100 points). (see fig.1) The SIR labelling system was developed by considering the established labelling system for buildings from the Minnesota Sustainable Design Guide [10].

The fourth phase of the project is still an ongoing activity at national level.

\section{Conclusions}

Sustainable or green building design is still an evolving field with rapid advances in knowledge, technology, and methods of measuring outcomes. Rating systems and guidelines continue to adapt and improve over time in order to answer the need of time. Sustainable development is a major concern and includes both environmental protection and energy management [14]. One of the largest end users of environmental resources and one of the largest polluters is the construction sector. One of the most important aims in improving buildings performance with regard to the environment is to encourage environmental responsibility and therefore give greater value on the welfare of future generations. The assessment methods provide a methodological framework to measure and monitor environmental performance of buildings and also alert the building profession to the importance of sustainable development in the building process. Thus energy management goals could be obtained by setting structured criteria for meeting the energy efficiency requirements on international and national level.

The methodology was designed and will be promoted as an "Implementation Guide" and will be presented to the beneficiaries of the rehabilitation work and to decision-makers (local government, ministries, and politicians). The guide gives a different and new perspective for the national sustainable development strategy and is meant to be an example for an integrated rehabilitation process.

Specialists will play a very important role in educating people and authorities in having a multi-criteria vision regarding efficiency and energy management in buildings when designing of new buildings and in the process of refurbishment of existing ones. 


\section{Acknowledgements}

The authors would like to thank all the partners involved in the SIR grant. The paper was made possible due to extensive work made by all partners in the project.

\section{References}

[1] Broto, C., New Trends in Renovating, Gingko Press, Barcelona, 2000.

[2] Dumitrescu, C., Georgescu, M. et al, Complex rehabilitation of sets of buildings housing: context, criteria and directions, Architecture Annals, No 3, pp. 16, 2009.

[3] Cotana, F., Goretti, M., BGP index: An approach to the certification of building global performance, Proceedings of Clima 2007 "Well Being Indoors", Helsinki, Finland, 2007.

[4] BRREAM 2004. Building research establishment environmental assessment method. http://www.breeam.org/

[5] W.L., Lee, Burnett, J., Benchmarking energy use assessment of HKBEAM, BREEAM and LEED, Building and Environment 43, pp. 18821894, (2008).

[6] Cole, J.R., Building environmental assessment methods: redefining intentions and roles, Building Research \& Information, 33:5, pp. 455-467, 2005.

[7] Cole, J.R., Shared markets: coexisting building environmental assessment methods, Building Research \& Information, 34:4, pp. 357-37, 2006.

[8] HK-BEAM Society Enhancing Hong Kong's Built Environment, HKBEAM Society, Hong Kong. 2005.

[9] US Green Building Council (USGBC) US Green Building Council website, 2013, (available at: http://new.usgbc.org/).

[10] Dumitrescu, C., SIR Symposium: Complex Rehabilitation, 2009.

[11] The State of Minnesota Sustainable Building Guidelines (MSBG), http://www.msbg.umn.edu

[12] Minnesota Sustainable Building Guidelines for New Buildings and Major Renovations, Version 2 .2 Update March 2013, www msbgtracking.com.

[13] Georgescu, M. et al, Research grant results S.I.R., "Ion Mincu" Academic publishing, Bucharest, 2011.

[14] K., Hall., The Green building bible, Vol. 1 + Vol. 2, 4th Edition, The Green Building Press, 2008, -13.

[15] Directive 2010/31/EU of the European Parliament and of the Council of 19 May 2010 on the energy performance of buildings. 